\title{
Rivaroxaban modulates electrical and mechanical characteristics of left atrium
}

\author{
Chien-Jung Chang ${ }^{1,2}$, Yao-Chang Chen ${ }^{3}$, Yung-Kuo Lin ${ }^{1,4}$, Jen-Hung Huang ${ }^{4}$, Shih-Ann Chen ${ }^{5}$ and Yi-Jen Chen ${ }^{1,4^{*}}$
}

\begin{abstract}
Background: Rivaroxaban reduces stroke in patients with atrial fibrillation (AF). Left atrium (LA) plays a critical role in the pathophysiology of AF. However, the electromechanical effects of rivaroxaban on LA are not clear.

Results: Conventional microelectrodes and a whole-cell patch-clamp were used to record the action potentials (APs) and ionic currents in rabbit LA preparations and isolated single LA cardiomyocytes before and after the administration of rivaroxaban. Rivaroxaban $(10,30,100$, and $300 \mathrm{nM})$ concentration-dependently reduced $\mathrm{LA}(n=7)$ AP durations at $90 \%$ repolarization $\left(A P D_{90}\right)$ from $76 \pm 2$ to $79 \pm 3,67 \pm 4$ ( $P<0.05$, vs. control), $59 \pm 5$, $(P<0.01$, vs. control), and $56 \pm 4$ ms $(\mathrm{P}<0.005$, vs. control), respectively. Rivaroxaban $(10,30,100$, and $300 \mathrm{nM})$ concentration-dependently increased the $L A(n=7)$ diastolic tension by $351 \pm 69(P<0.05$, vs. control), $563 \pm 136(P<0.05$, vs. control), $582 \pm 119(P<0.05$, vs. control), and $603 \pm 108 \mathrm{mg}(P<0.005$, vs. control), respectively, but did not change LA contractility. In the presence of L-NAME $(100 \mu \mathrm{M})$ and indomethacin $(10 \mu \mathrm{M})$, additional rivaroxaban (300 $\mathrm{nM})$ treatment did not significantly further increase the $\mathrm{LA}(n=7)$ diastolic tension, but shortened the $\mathrm{APD}_{90}$ from $73 \pm 2$ to $60 \pm 6 \mathrm{~ms}(P<0.05$, vs. control). Rivaroxaban $(100 \mathrm{nM})$ increased the L-type calcium current and ultra-rapid delayed rectifier potassium current, but did not change the transient outward potassium current in isolated LA cardiomyocytes.
\end{abstract}

Conclusions: Rivaroxaban modulates $L A$ electrical and mechanical characteristics with direct ionic current effects.

Keywords: Rivaroxaban, Atrial fibrillation, Factor Xa, Nitric oxide synthase, Cyclooxygenase

\section{Background}

Arial fibrillation (AF) is the most common sustained arrhythmia which predisposes to early activation of platelets, induction of coagulation factors, and ultimately formation of thrombi in left atrium (LA), which contributes to thromboembolic morbidity and mortality $[1,2]$. LA plays a major role in the genesis of AF, and also harbors activated platelets and increased prothrombotic factors [2]. These AF-activated prothrombotic factors, activated factor X (FXa) and downstream thrombin, may exert their electromechanical effects on cardiomyocytes other than thrombosis through activating proteaseactivated receptors (PARs) [3]. FXa elicits intracellular signaling responses through the activated PAR2 and

\footnotetext{
* Correspondence: yjchen@tmu.edu.tw

'Graduate Institute of Clinical Medicine, College of Medicine, Taipei Medical University, Taipei, Taiwan

${ }^{4}$ Division of Cardiovascular Medicine, Department of Internal Medicine, Wan Fang Hospital, Taipei Medical University, 111 Hsin-Lung Road Sec. 3, Taipei 116, Taiwan

Full list of author information is available at the end of the article
}

possibly also through PAR1 in endothelial and smooth muscle cells [4]. Activated PAR1 coupled with $G_{q}, G_{i}$, and/or $\mathrm{G}_{12 / 13}$ stimulation mediated nitric oxide (NO) production by NO synthase (NOS) [5]. In various tissues, PAR2 activation caused arachidonic acid release and prostanoid formation which involved cyclooxygenase (COX) induction via multiple signaling pathways [5]. Accordingly, AF-induced FXa which activates PAR1 and PAR2 could modulate LA electrical and mechanical characteristics through $\mathrm{NO}$ and prostanoid formation $[5,6]$.

Rivaroxaban selectively binds to the FXa and reduces thrombin formation, which prevents stroke in AF patients [7]. However, it is not clear whether rivaroxaban modulates electrical and mechanical characteristics of the LA. The purposes of this study were to investigate the electrical and mechanical effects of rivaroxaban on LA and evaluate the roles of NOS and COX in the effects of FXa. 


\section{Methods}

Electromechanical and pharmacological studies of the LA preparations

Experiments in this study conformed to the institutional Guide for the Care and Use of Laboratory Animals. Male rabbits (weighing $1 \sim 2 \mathrm{~kg}$ ) were anesthetized with an intraperitoneal injection of sodium pentobarbital $(100 \mathrm{mg} / \mathrm{kg})$. A midline thoracotomy was then performed, and the heart and lungs were removed as described previously $[8,9]$. To dissect the LA, the LA was opened by an incision along the mitral valve annulus, extending from the coronary sinus to the septum, in Tyrode's solution with a composition (in $\mathrm{mM}$ ) of 137 $\mathrm{NaCl}, 4 \mathrm{KCl}, 15 \mathrm{NaHCO}_{3}, 0.5 \mathrm{NaH}_{2} \mathrm{PO}_{4}, 0.5 \mathrm{MgCl}_{2}, 2.7$ $\mathrm{CaCl}_{2}$, and 11 dextrose. Preparations were connected to a WPI model FD223 electrometer under a tension of $150 \mathrm{mg}$ as described previously $[10,11]$. One end of the preparations was pinned with needles to the bottom of a tissue bath. The other end was connected to a Grass FT03C force transducer with a silk thread. The adventitial or epicardial side of the preparations faced upwards. The LA tissue strips were superfused at a constant rate $(3 \mathrm{ml} / \mathrm{min})$ with Tyrode's solution saturated with a 97\% $\mathrm{O}_{2}-3 \% \quad \mathrm{CO}_{2}$ gas mixture. The temperature was maintained at $37^{\circ} \mathrm{C}$, and the preparations were allowed to equilibrate for $1 \mathrm{~h}$ before the electrophysiological assessment.

Transmembrane action potentials (APs) were recorded by machine-pulled glass capillary microelectrodes filled with $3 \mathrm{~mol} / \mathrm{L}$ of $\mathrm{KCl}$ which were connected to a WPI Duo 773 electrometer under a tension of $150 \mathrm{mg}$. Electrical and mechanical events (contractile force and diastolic tension) were simultaneously displayed on a Gould 4072 oscilloscope and a Gould TA11 recorder. Using a data acquisition system, signals were recorded with DC coupling and a $10-\mathrm{kHz}$ low-pass filter cutoff frequency. Signals were recorded digitally with a 16-bit accuracy at a rate of $125 \mathrm{kHz}$. Electrical stimulation was provided using a Grass S88 stimulator through a Grass SIU5B stimulus isolation unit. The AP amplitude (APA) was obtained by measuring the difference between the resting membrane potential (RMP) or maximum diastolic potential and the peak of AP depolarization. AP durations (APDs) at repolarization of $90 \%, 50 \%$, and $20 \%$ of the APA were respectively measured as $\mathrm{APD}_{90}, \mathrm{APD}_{50}$, and $\mathrm{APD}_{20}$. The RMP, APA, $\mathrm{APD}_{90}, \mathrm{APD}_{50}, \mathrm{APD}_{20}$, and
a. Control
b. Rivaroxaban $10 \mathrm{nM}$
c. Rivaroxaban $30 \mathrm{nM}$
d. Rivaroxaban $100 \mathrm{nM}$
e. Rivaroxaban $300 \mathrm{nM}$
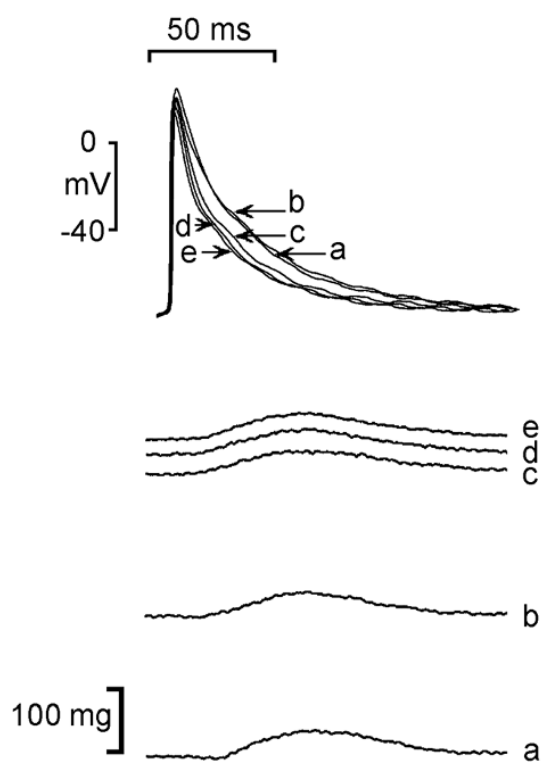
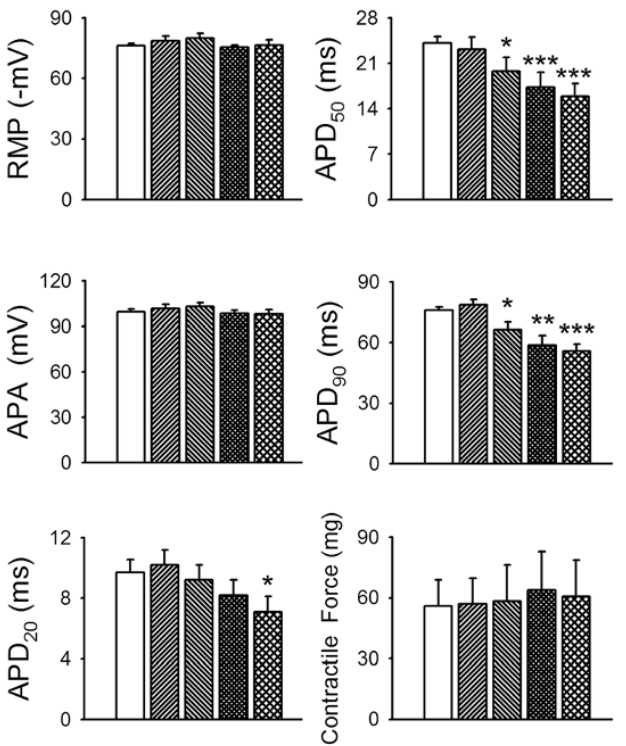

Figure 1 Effects of rivaroxaban on the left atrial (LA) action potential (AP) and contractility. An example and average data $(n=7)$ show that rivaroxaban $(10,30,100$, and $300 \mathrm{nM})$ concentration-dependently shortened $A P$ durations $\left(A P D_{20}, A P D_{50}\right.$, and $\left.A P D_{90}\right)$ of $L A$. The resting membrane potential (RMP), AP amplitude (APA), and contractile forces of LA did not significantly change with rivaroxaban treatment. ${ }^{*} \mathrm{P}<0.05$, ${ }^{* *} \mathrm{P}<0.01,{ }^{* * *} \mathrm{P}<0.005$ vs. control. 
contractile forces were measured under $2-\mathrm{Hz}$ pacing of the LA before and after the sequential administration of rivaroxaban $(10,30,100$, and $300 \mathrm{nM})$. In order to study the mechanical effects of rivaroxaban, an $\mathrm{N}^{\mathrm{G}}$-nitro- $\mathrm{L}$ arginine methyl ester (L-NAME) solution (an NOS inhibitor, $100 \mu \mathrm{M}$ ) and indomethacin (a non-selective COX inhibitor, $10 \mu \mathrm{M}$ ) solution and rivaroxaban solution $(300 \mathrm{nM})$ were sequentially added to LA preparations.

\section{Isolation of LA cardiomyocytes and a whole-cell patch-clamp}

Single LA myocytes were enzymatically dissociated through the same procedure as described previously [12]. A whole-cell perforated with amphotericin B of $300 \mu \mathrm{g} / \mathrm{ml}$ (for L-type calcium current, $I_{\mathrm{Ca}-\mathrm{L}}$ ) or ruptured (for others) patch clamp was performed in single isolated cardiomyocyte before and after the administration of rivaroxaban (100 $\mathrm{nM})$ using an Axopatch 1D amplifier (Axon Instruments, Foster City, CA, USA) at $35 \pm 1^{\circ} \mathrm{C}$ [12]. Borosilicate glass electrodes (o.d., $1.8 \mathrm{~mm}$ ) with tip resistances of $3 \sim 5 \mathrm{M} \Omega$ were used. Before the formation of the membrane-pipette seal, the tip potentials were zeroed in Tyrode's solution. The junction potentials between the bath and pipette solution $(9 \mathrm{mV})$ were corrected for the AP recordings. APs were recorded in the current-clamp mode, and the ionic currents were recorded in the voltage-clamp mode. A small hyperpolarizing step from a holding potential of $-50 \mathrm{mV}$ to a test potential of $-55 \mathrm{mV}$ for $80 \mathrm{~ms}$ was delivered at the beginning of each experiment. The area under the capacitative currents was divided by the applied voltage step to obtain the total cell capacitance. Normally $60 \% \sim 80 \%$ series resistance (Rs) was electronically compensated for. APs were elicited in cells from the LA through brief current pulses at $1 \mathrm{~Hz}$. The extracellular solution contained the basic composition (in $\mathrm{mM}$ ) of $\mathrm{NaCl}$ 137, $\mathrm{KCl}$ 5.4, HEPES 10, $\mathrm{MgCl}_{2}$ 0.5, $\mathrm{CaCl}_{2}$ 1.8, and glucose 10. The solution was titrated to a pH of 7.4 with $\mathrm{NaOH}$. Micropipettes were filled with a solution containing (in $\mathrm{mM}$ ) $\mathrm{CsCl} 130, \mathrm{MgCl}_{2} 1, \mathrm{Mg}_{2}$ ATP 5, HEPES 10, EGTA 10, NaGTP 0.1, and $\mathrm{Na}_{2}$ phosphocreatine 5 , (adjusted to a $\mathrm{pH}$ of 7.2 with $\mathrm{CsOH}$ ) for the $I_{\mathrm{Ca}-\mathrm{L}}$ and containing (in $\mathrm{mM}$ ) $\mathrm{KCl} 20, \mathrm{~K}$ aspartate 110 , $\mathrm{MgCl}_{2}$ 1, $\mathrm{Mg}_{2}$ ATP 5, HEPES 10, EGTA 0.5, LiGTP 0.1, and $\mathrm{Na}_{2}$ phosphocreatine 5 , (adjusted to a $\mathrm{pH}$ of 7.2 with $\mathrm{KOH}$ ) for the AP and potassium currents. The $I_{\mathrm{Ca}-\mathrm{L}}$ was measured as an inward current during depolarization from a holding potential of $-50 \mathrm{mV}$ to testing potentials ranging from -40 to $+60 \mathrm{mV}$ in $10-\mathrm{mV}$ steps for $300 \mathrm{~ms}$ at a frequency of $0.1 \mathrm{~Hz}$. The $\mathrm{NaCl}$ and $\mathrm{KCl}$ in the

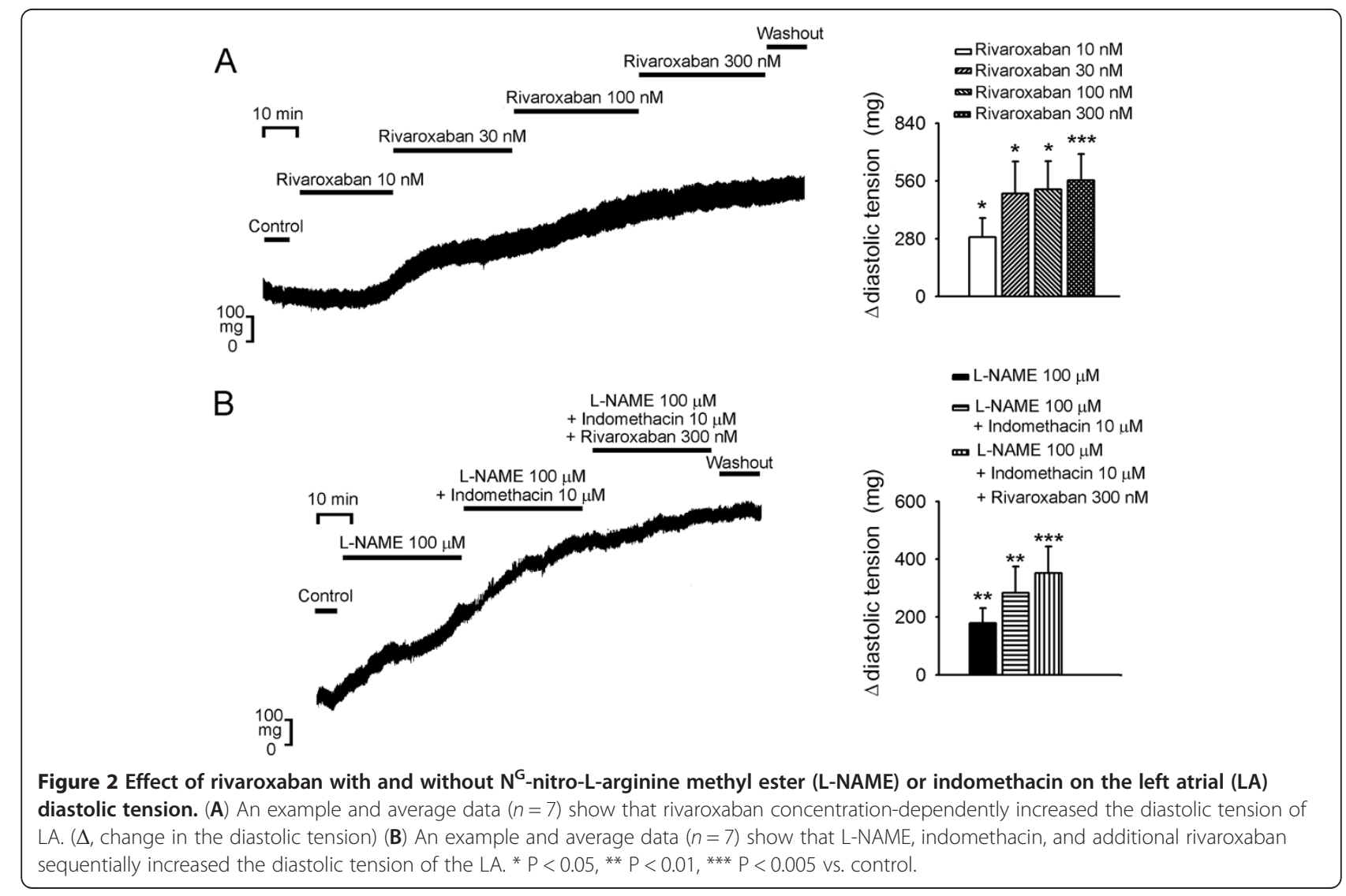


external solution were respectively replaced by $\mathrm{TEACl}$ and $\mathrm{CsCl}$. The transient outward potassium current $\left(I_{\text {to }}\right)$ was studied with a double-pulse protocol. A 30-ms pre-pulse from -80 to $-40 \mathrm{mV}$ was used to inactivate the sodium channels, followed by a $300-\mathrm{ms}$ test pulse to $+60 \mathrm{mV}$ in $10-\mathrm{mV}$ steps at a frequency of $0.1 \mathrm{~Hz}$. $\mathrm{CdCl}_{2}(200 \mu \mathrm{M})$ was added to the bath solution to inhibit the $I_{\mathrm{Ca}-\mathrm{L}}$. The $I_{\mathrm{to}}$ was measured as the difference between the peak outward current and steady-state current [13]. The ultra-rapid delayed rectifier potassium current $\left(I_{\text {Kur }}\right)$ was studied with a double-pulse protocol, consisting of a 100-ms depolarizing pre-pulse to $+40 \mathrm{mV}$ from a holding potential of $-50 \mathrm{mV}$, followed by $150-\mathrm{ms}$ voltage steps from -40 to $+60 \mathrm{mV}$ in $10-\mathrm{mV}$ increments at room temperature to provide an adequate temporal resolution. The $I_{\text {Kur }}$ was measured as 4-aminopyridine (1 mM)-sensitive currents [14,15].

\section{Statistical analysis}

All continuous variables are expressed as the mean \pm standard error of the mean (SEM). A one-way repeated- measures analysis of variance (ANOVA) was used to compare the difference before and after drug administration on LA. The electrophysiological and mechanical characteristics between different groups were compared by a Wilcoxon rank-sum test or unpaired $t$-test depending on the outcome of the normality test. A P value of less than 0.05 was considered statistically significant.

\section{Results}

Rivaroxaban affects the electric and mechanical characteristics of LA

As shown in Figure 1, rivaroxaban $(10,30,100$, and $300 \mathrm{nM}$ ) concentration-dependently reduced the $\mathrm{APD}_{20}$, $\mathrm{APD}_{50}$, and $\mathrm{APD}_{90}$ in LA. However, rivaroxaban did not significantly affect the RMP, APA, or contractile force of LA. Moreover, rivaroxaban $(10,30,100$, and $300 \mathrm{nM})$ concentration-dependently increased LA diastolic tension, which could not be reversed after washout for $30 \mathrm{~min}$ (Figure 2A). The treatment with L-NAME $(100 \mu \mathrm{M})$, add-on indomethacin $(10 \mu \mathrm{M})$, and additional rivaroxaban $(300 \mathrm{nM})$ increased the LA diastolic

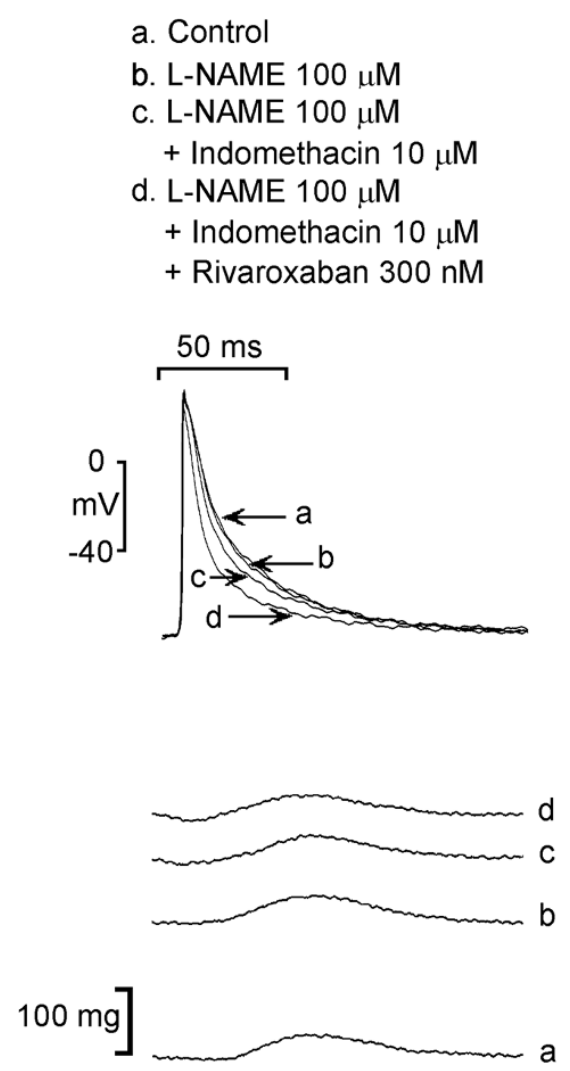

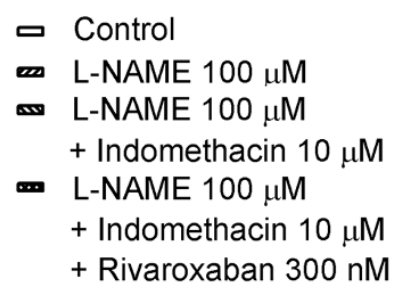
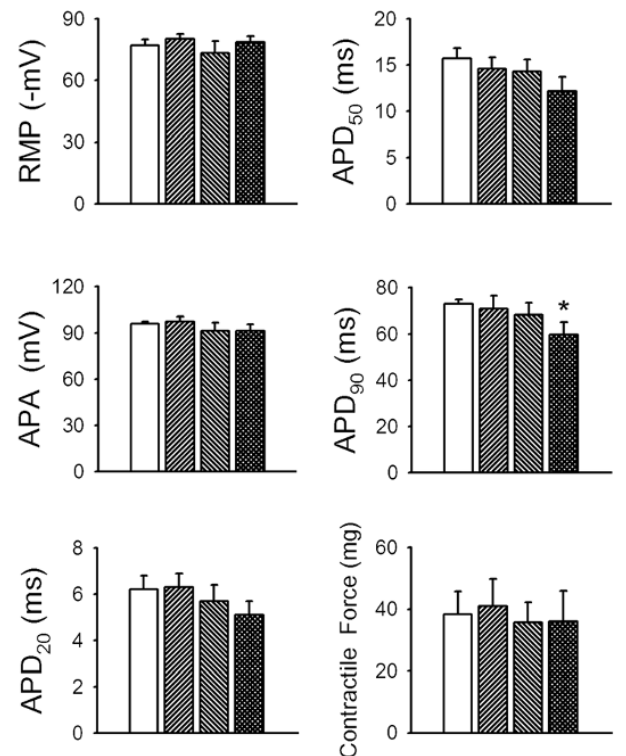

Figure 3 Effects of rivaroxaban $(300 \mathrm{nM})$ with and without $\mathrm{N}^{\mathrm{G}}$-nitro-L-arginine methyl ester (L-NAME, $\left.100 \mu \mathrm{M}\right)$, or indomethacin (10 $\left.\mu \mathrm{M}\right)$ and on the left atrial (LA) action potential (AP) and contractility. An example and average data $(n=7)$ show that rivaroxaban $(10,30$, 100, and $300 \mathrm{nM}$ ) solutions concentration-dependently shortened the $90 \%$ repolarization of the AP duration (APD 90 ) of $L A$. The resting membrane potential (RMP), AP amplitude (APA), and contractile forces of LA did not significantly change with L-NAME, indomethacin and additional rivaroxaban treatment. ${ }^{*} P<0.05$ vs. control. 
tension as compared to control, respectively (Figure 2B), but did not affect contractile forces of LA (Figure 3). In addition, the increment in diastolic tension by L-NAME was less than that in the LA treated with $30 \mathrm{nM}$ rivaroxaban $(\mathrm{P}<0.05), 100 \mathrm{nM}$ rivaroxaban $(\mathrm{P}<0.05)$, and $300 \mathrm{nM}$ rivaroxaban $(\mathrm{P}<0.05)$. In the presence of L-NAME, indomethacin administration $(10 \mu \mathrm{M})$ further increased the LA diastolic tension which was comparable to that of LA treated with rivaroxaban (30, 100 , and $300 \mathrm{nM})$. In the presence of L-NAME and indomethacin, the additional rivaroxaban (300 $\mathrm{nM}$ ) treatment did not further significantly increase the LA diastolic tension, and the overall increment in the LA diastolic tension after treatment of rivaroxaban (300 nM) did not differ in the presence or absence of L-NAME and indomethacin.

As shown in Figure 3, in the presence of L-NAME $(100 \mu \mathrm{M})$ and indomethacin $(10 \mu \mathrm{M})$, additional treatment with rivaroxaban $(300 \mathrm{nM})$ significantly shortened the $\mathrm{APD}_{90}$ but did not affect the RMP or APA of LA.

\section{Effects of rivaroxaban on AP configurations in LA myocytes}

Rivaroxaban had rapid effects on the electrical activity of LA myocytes and reached a steady state in $3 \sim 5 \mathrm{~min}$ after its superfusion. Figure 4 presents examples of the

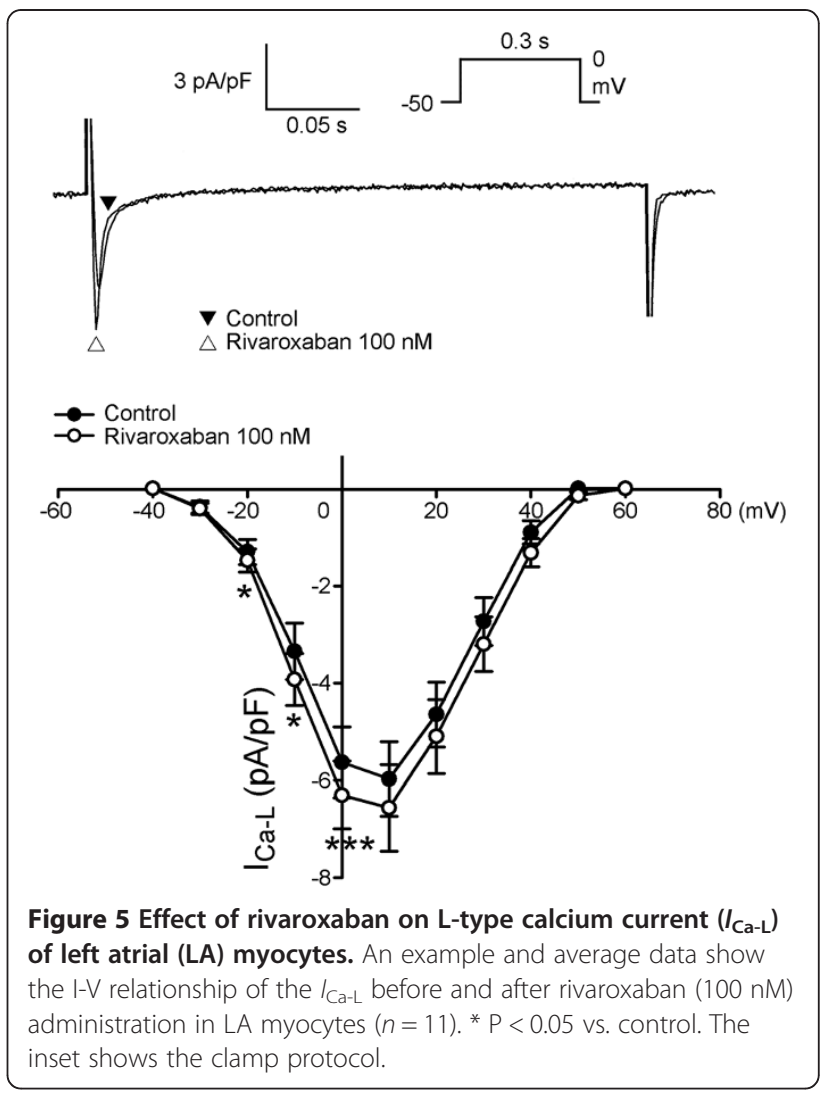

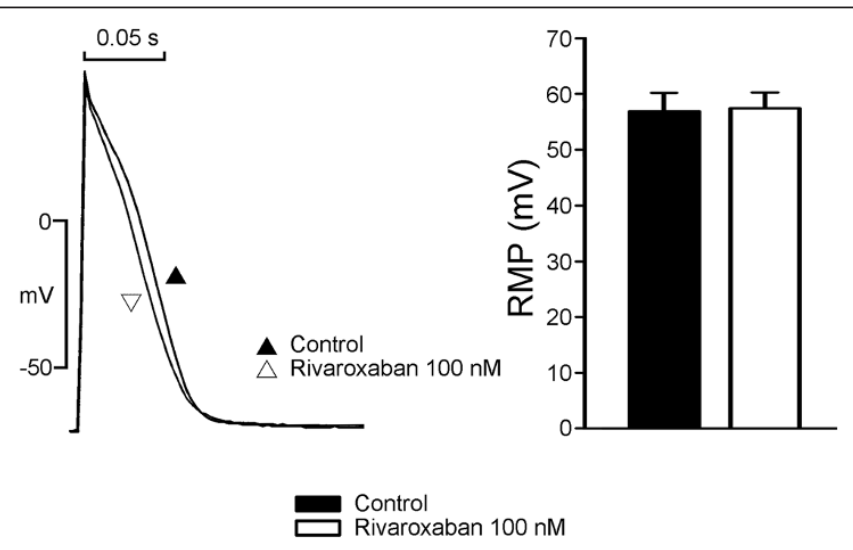
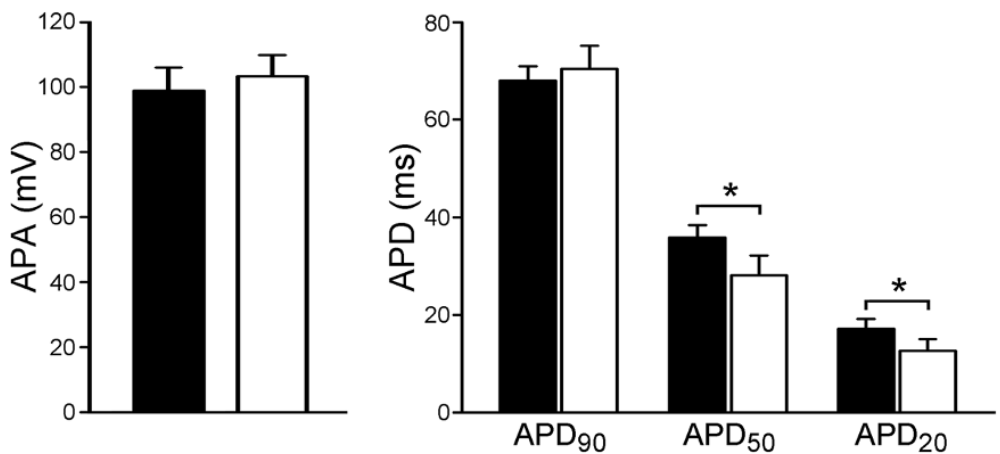

Figure 4 Effects of rivaroxaban on isolated left atrial (LA) myocytes. An example and average data show that rivaroxaban shortened the action potential durations $\left(\mathrm{APD}_{20}\right.$ and $\left.\mathrm{APD}_{50}\right)$ of $\mathrm{LA}(n=7)$. ${ }^{*} \mathrm{P}<0.05$ vs. control. 

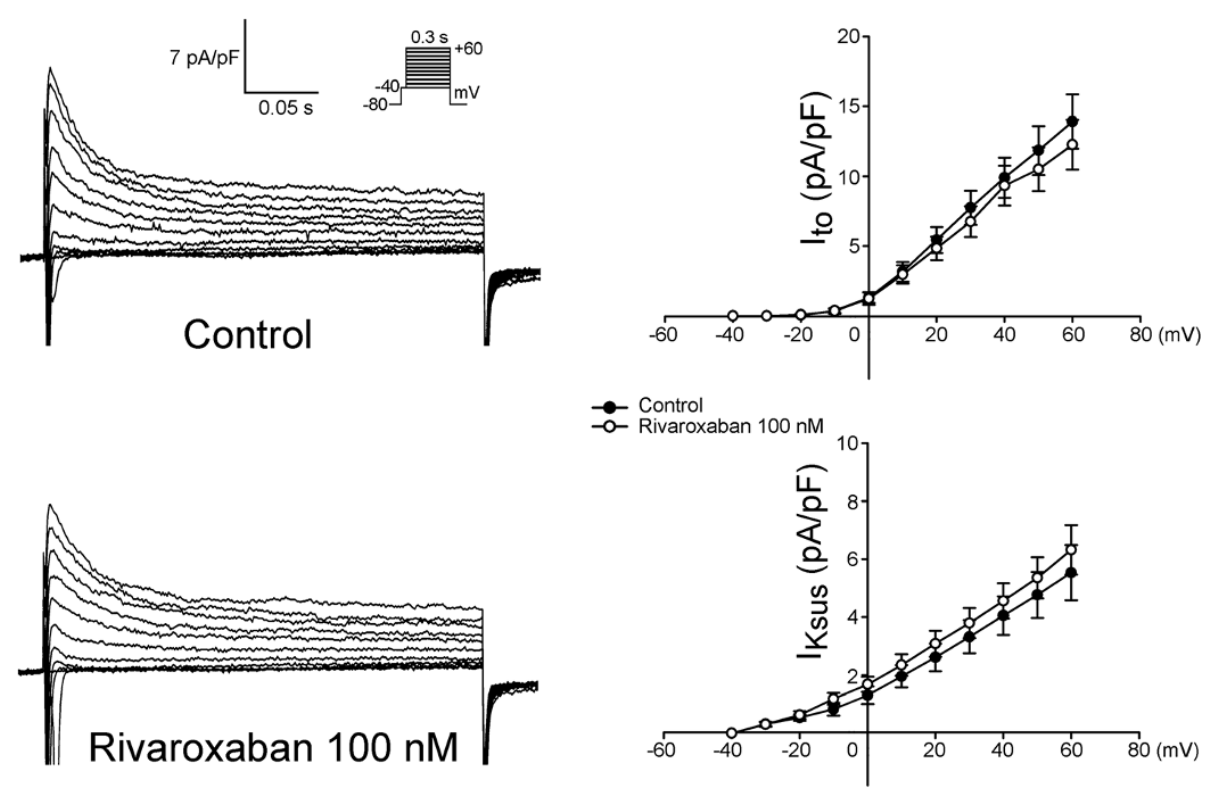

Figure 6 Effects of rivaroxaban on the transient outward current $\left(I_{\text {to }}\right)$ of left atrial (LA) myocytes. An example and average data show the I-V relationship of the Ito before and after rivaroxaban administration in LA myocytes $(n=12)$. The inset shows the clamp protocol.

AP morphology of LA myocytes before and after rivaroxaban $(100 \mathrm{nM})$ administration $(n=7)$. Superfusion with rivaroxaban significantly reduced $\mathrm{APD}_{50}$ and $\mathrm{APD}_{20}$ in LA myocytes. However, rivaroxaban $(100 \mathrm{nM})$ did not affect the APA or RMP in LA myocytes.

\section{Effect of rivaroxaban on membrane currents of LA myocytes}

Figure 5 shows tracings and the I-V relationship of the $I_{\mathrm{Ca}-\mathrm{L}}$ before and after rivaroxaban $(100 \mathrm{nM})$ administration in LA myocytes, and it was found that rivaroxaban increased the peak $I_{\mathrm{Ca}-\mathrm{L}}$ by $11.8 \%$ (elicited from $-40 \mathrm{mV}$ to $+60 \mathrm{mV}, n=11)$. However, as shown in Figure 6, rivaroxaban $(100 \mathrm{nM})$ did not significantly change the $I_{\mathrm{to}}$. Moreover, Figure 7 shows that rivaroxaban $(100 \mathrm{nM})$ significantly increased the peak $I_{\text {Kur }}$ by $29.6 \%$ (elicited from $-40 \mathrm{mV}$ to $+60 \mathrm{mV}, n=12$ ).

\section{Discussion}

To reduce thromboembolic complications with AF, several new antithrombotic agents were developed with non-inferior antithrombotic effects and fewer hemorrhagic complications than the traditional vitamin $K$ antagonist [16,17]. It's well known that AFactivated prothrombotic factors, activated factor $\mathrm{X}$ (FXa) and downstream thrombin, exert their electromechanical effects on cardiomyocytes other than thrombosis through activating protease-activated receptors (PARs) [3]. Accordingly, the reduction in FXa

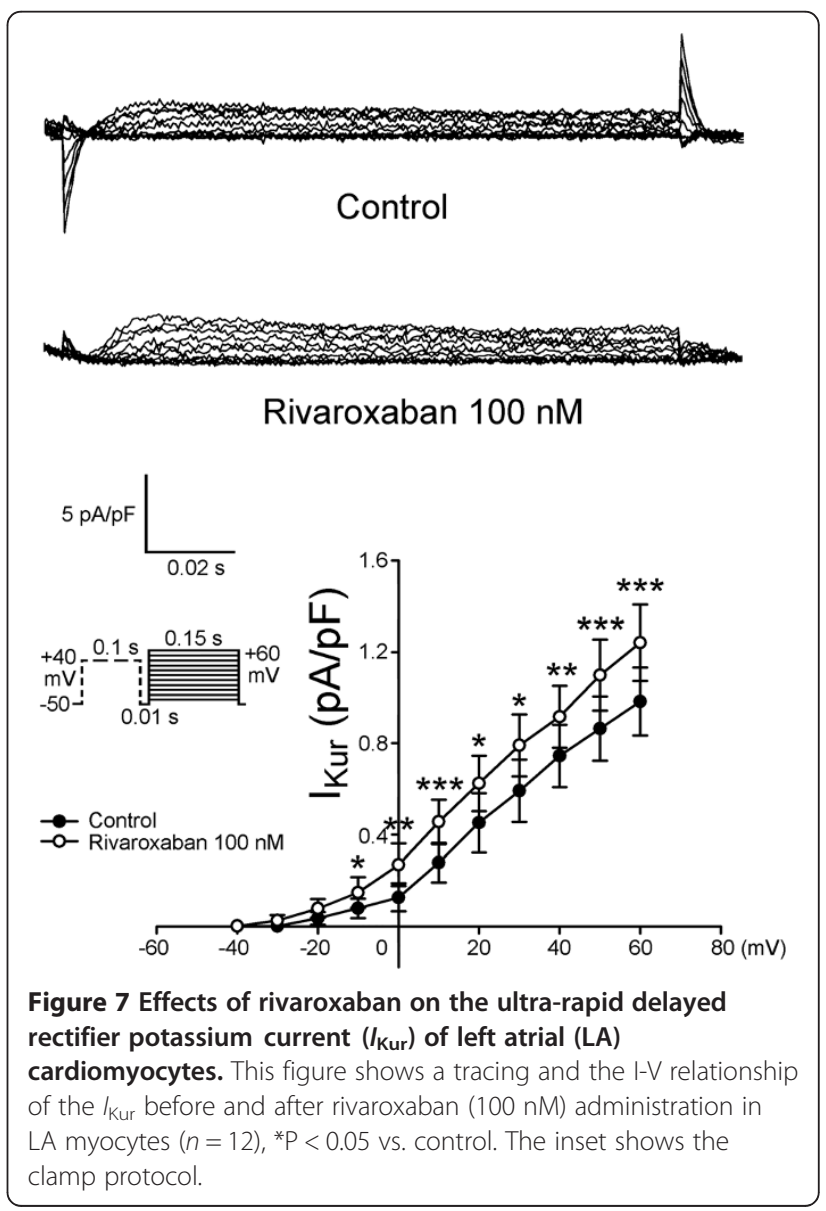


may also modulate electrical and mechanical characteristics of the LA by inhibiting $\mathrm{NO}$ and prostanoid $[4,5]$. This study attempted to investigate the electrical and mechanical effects of rivaroxaban on LA at comparable physiological doses and also evaluated the inhibitors of NOS and COX. Rivaroxaban reversibly bound to the FXa and diminished PAR1 and PAR2 activation. These two activated G-protein-coupled receptors promote the production of prostanoid and NO which induce vascular dilatation and reduce wall tension. In this study, rivaroxaban administration resulted in concentration-dependent shortening of APDs (Figure 1) and an increasing wall tension of LA (Figure 3). Moreover, in Figures 1 and 3, the diastolic tension increased earlier (with $10 \mathrm{nM}$ rivaroxaban) than the occurrence of APD shortening (with $30 \mathrm{nM}$ rivaroxaban). The earlier increased wall tension may also have contributed to the shortening of the AP through mechanoelectrical feedback [18-20], in addition to the direct effects of rivaroxaban on LA cardiomyocytes. According to a previous study, stretching of myocardiocytes shortened the APD, which implies a possible mechanism of electric modulation by rivaroxaban [21]. A maximal plasma concentration $\left(\mathrm{C}_{\max }\right)$, of around $125 \mu \mathrm{g} / \mathrm{L}$ or $300 \mathrm{nM}$, of rivaroxaban was reached within $2 \sim 4 \mathrm{~h}$ after oral administration after a single oral dose in healthy volunteers $[22,23]$. Therefore, the concentrations used in this experiment are clinically relevant. However, there is no report available so far to show that rivaroxaban administered at clinically relevant dose increases atrial diastolic pressure. Moreover, this study did not evaluate the effects of rivaroxaban $(300 \mathrm{nM})$ alone or L-NAME with rivaroxaban on LA.

In this study, we found that L-NAME significantly increased the LA wall tension but this effect is less than that by rivaroxaban. This finding implied that blockage of NOS mediated a portion of the effects of rivaroxaban on LA to increase the wall tension. Additional administration of indomethacin, which blocked COX and reduced prostanoid production, further elevated the wall tension of LA to a level comparable to that induced by rivaroxaban. In the presence of L-NAME and indomethacin, the additional administration of rivaroxaban $(300 \mathrm{nM})$ did not significantly increase the wall tension, but the total increment in the wall tension was comparable to the increase by rivaroxaban $(300 \mathrm{nM})$ as shown in Figure 2. The blockage of the FXa by rivaroxaban reduced the production of $\mathrm{NO}$ and prostanoid, which coordinately increased the wall tension of LA. The blockage of NOS by L-NAME represented a partial mechanical effect, while the additional blockage of COX by indomethacin seemed to nearly complete the mechanical effect of rivaroxaban on LA. However, the sequential addition of L-NAME and indomethacin did not significantly change the APDs, but additional rivaroxaban $(300 \mathrm{nM})$ treatment shortened the $\mathrm{APD}_{90}$ compared to the baseline (Figure 2). It is not clear whether this electrical effect of rivaroxaban on LA is directly mediated by rivaroxaban or resulted from diminished activation of PARs. Besides, we also didn't use the NOS and COX activator to elucidate the mechanisms of rivaroxaban-increased diastolic tension in LA or their direct AP and ionic effects in isolated LA myocytes.

In experiments on isolated single myocytes, we found that rivaroxaban $(100 \mathrm{nM})$ shortened the $\mathrm{APD}_{20}$ and $\mathrm{APD}_{50}$, but did not affect the $\mathrm{APD}_{90}$, RMP, or APA. The less shortening of the APD in isolated single cardiomyocyte by rivaroxaban suggested that the greater shortening of APD in LA tissue preparations may have been caused by mechanoelectrical feedback due to the increased wall tension with stretched myocytes in tissue preparation experiments. The ionic current experiments showed that rivaroxaban did not change the $I_{\text {to }}$ but significantly increased the $I_{\text {Kur }}$ which may have contributed to its effect in shortening the APD. Rivaroxaban also increased the $I_{\mathrm{Ca}-\mathrm{L}}$, which may have been a result of repolarization homeostasis and implies that the increasing LA wall tension was due to intracellular calcium loading. These findings suggest that rivaroxaban at clinically relevant concentrations directly affects ionic currents in LA myocytes. In order to correlate the clinical settings, we use $100 \mathrm{nM}$ of rivaroxaban to measure its ionic current effects, which are closely related to the known plasma concentrations in humans [24]. However, it is not clear whether the higher concentration of rivaroxaban $(300 \mathrm{nM})$ may have stronger ionic effects. Moreover, we did not use purified FX in the tissue preparation experiments to elucidate its potential competition effects to rivaroxaban.

\section{Conclusions}

Rivaroxaban modulates LA electrical characteristics with direct effects on ionic currents, and regulates mechanical characteristics, which can be attenuated by the inhibitions on NOS and COX.

\section{Competing interests}

The authors declare that they have no competing interests.

\section{Authors' contributions}

CJC and YKL interpreted the data and drafted the manuscript. YCC and JHH performed the experiments and revised it for scientific content. SAC and YJC conceived of this study, and participated in its design and coordination. All authors read and approved the final manuscript.

\section{Acknowledgements}

The current study was supported by grants (NSC99-2314-B-016-034-MY3, NSC99-2628-B-038-011-MY3, NSC100-2628-B-038-001-MY4, and NSC1002314-B-038-027-MY3) from the National Science Council, Taiwan, and (101swf01, 101-wf-eva-05, 102-wf-phd-02, and 102-wf-eva-15) from Wan Fang Hospital, Taipei Medical University. 


\section{Author details}

'Graduate Institute of Clinical Medicine, College of Medicine, Taipei Medical University, Taipei, Taiwan. ${ }^{2}$ Division of Cardiology, Tungs' Taichung Metroharbor Hospital, Taichung, Taiwan. ${ }^{3}$ Department of Biomedical Engineering and Institute of Physiology, National Defense Medical Center, Taipei, Taiwan. ${ }^{4}$ Division of Cardiovascular Medicine, Department of Internal Medicine, Wan Fang Hospital, Taipei Medical University, 111 Hsin-Lung Road Sec. 3, Taipei 116, Taiwan. ${ }^{5}$ Division of Cardiology and Cardiovascular Research Center, Taipei Veterans General Hospital, Taipei, Taiwan.

Received: 26 December 2012 Accepted: 11 March 2013

Published: 15 March 2013

\section{References}

1. Zabalgoitia M, Halperin JL, Pearce LA, Blackshear JL, Asinger RW, Hart RG Transesophageal echocardiographic correlates of clinical risk of thromboembolism in nonvalvular atrial fibrillation. J Am Coll Cardiol 1998, 31:1622-1626.

2. Ren JF, Marchlinski FE, Callans DJ, Gerstenfeld EP, Dixit S, Lin D, Nayak HM, Hsia $\mathrm{HH}$ : Increased intensity of anticoagulation may reduce risk of thrombus during atrial fibrillation ablation procedures in patients with spontaneous echo Contrast. J Cardiovasc Electrophysiol 2005, 16:474-477.

3. Rana S, Yang L, Hassanian SM, Rezaie AR: Determinants of the specificity of protease-activated receptors 1 and 2 signaling by factor $\mathrm{Xa}$ and thrombin. J Cell Biochem 2012, 113:977-984.

4. Yang Z, Arnet U, Bauer E, Segesser LV, Siebenmann R, Turina M, Luscher TF: Thrombin-induced endothelium-dependent inhibition and direct activation of platelet-vessel wall interaction: role of prostacycline, nitric oxide, and thromboxane A2. Circulation 1994, 89:2266-2272.

5. Kang KW, Choi SY, Cho MK, Lee CH, Kim SG: Thrombin induces nitric-oxide synthase via $\mathrm{G}_{\mathrm{a12/13}}$-coupled protein kinase C-dependent I-kBA phosphorylation and JNK-medicated I-KBA degradation. J Biol Chem 2003, 278:17368-17378.

6. Kawabata A, Kawao N: Physiology and pathophysiology of proteinaseactivated receptors (PARs): PARs in the respiratory system: cellular signaling and physiological/pathological roles. J Pharmacol Sci 2005, 97:20-24.

7. Patel MR, Mahaffey KW, Garg J, Pan G, Singer DE, Werner Hacke W, Breithardt G, Halperin JL, Hankey GJ, Piccini JP, Becker RC, Nessel CC, Paolini JF, Berkowitz SD, Fox KAA, Califf RM, ROCKET AF Steering Committee, for the ROCKET AF Investigators: Rivaroxaban versus warfarin in nonvalvular atrial fibrillation. N Engl J Med 2011, 365:883-891.

8. Tsai CF, Chen YC, Lin YK, Chen SA, Chen YJ: Electromechanical effects of the direct renin inhibitor (aliskiren) on the pulmonary vein and atrium. Basic Res Cardiol 2011, 106:163-174.

9. Tsai WC, Chen YC, Lin YK, Chen SA, Chen YJ: Sex differences in the electrophysiological characteristics of pulmonary veins and left atrium and their clinical implication in atrial fibrillation. Circ Arrhyth Electrophysiol 2011, 4:550-559.

10. Lin YK, Chen YC, Cheng CC, Lin FZ, Lin Cl, Chen SA, Chen YJ: Interactions of aging and hydrogen peroxide on pulmonary vein electrical activity: implications in the pathophysiology of atrial fibrillation. Acta Cardiol Sin 2011, 27:109-114.

11. Lin YK, Chen YC, Chen JH, Chen SA, Chen YJ: Adipocytes modulate the electrophysiology of atrial myocytes: implications in obesity-induced atrial fibrillation. Basic Res Cardiol 2011, 107:293-303.

12. Chen YJ, Chen YC, Wongcharoen W, Lin Cl, Chen SA: Effect of K201, a nove antiarrhythmic drug on calcium handling and arrhythmogenic activity of pulmonary vein cardiomyocytes. Br J Pharmacol 2008, 153:915-925.

13. Suenari K, Chen YC, Kao YH, Cheng CC, Lin YK, Chen YJ, Chen SA: Discrepant electrophysiological characteristics and calcium homeostasis of left atrial anterior and posterior myocytes. Basic Res Cardiol 2011, 106:65-74.

14. Udyavar AR, Chen YC, Chen YJ, Cheng CC, Lin Cl, Chen SA: Endothelin-1 modulates the arrhythmogenic activity of pulmonary veins. J CardiovasC Electrophysiol 2008, 19:285-292.

15. Brandt MC, Priebe L, Bohle T, Sudkamp M, Beuckelmann DJ: The ultrarapid and the transient outward $\mathrm{K}(+)$ current in human atrial fibrillation. Their possible role in postoperative atrial fibrillation. $J$ Mol Cell Cardiol 2000, 32:1885-1896
16. Turpie AGG: Oral, direct Factor Xa inhibitors in development for the prevention and treatment of thromboembolic diseases. Arterioscler Thromb Vasc Biol 2007, 27:1238-1247.

17. Perzborn E, Roehrig S, Straub A, Kubitza D, Mueck W, Laux V: Rivaroxaban: a new oral factor Xa inhibitor. Arterioscler Thromb Vasc Biol 2010, 30:376-381.

18. Fedorov W, Trifonova OP, Glukhov AV, Beloshapko GG, lushmanova AV: The role of atrial pressure in spontaneous initiation of atrial fibrillation in the dog. Kardiologiia 2004, 44(12):51-63.

19. Chan SL, Chen YC, Chen YJ, Wangcharoen W, Lee SH, Lin Cl, Chen SA: Mechanoelectrical feedback regulates the arrhythmogenic activity of pulmonary veins. Heart 2007, 93:82-88.

20. Lin YK, Lu YY, Chen YC, Chen YJ, Chen SA: Nitroprusside modulates pulmonary vein arrhythmogenic activity. J Biomed Sci 2011, 17:20-29.

21. Youm JB, Han J, Kim N, Zhang YH, Kim E, Joo H, Leem CH, Kim SJ, Cha KA, Earm YE: Role of stretch-activated channels on the stretch-induced changes of rate atrial myocytes. Prog in Biophysi and Molecu Biol 2006, 90:186-206.

22. Kubitza D, Becka M, Voith B, Zuehlsdorf M, Wensing G: Safety, pharmacodynamics, and pharmacokinetics of single doses of BAY 59-7939, an oral, direct factor Xa inhibitor. Clin Pharmacol Ther 2005, 78:412-421.

23. Kubitza D, Becka M, Mueck W, Zuehlsdorf M: Rivaroxaban (BAY 59-7939) an oral, direct Factor Xa inhibitor - has no clinically relevant interaction with naproxen. Br J Clin Pharmacol 2006, 63:469-476.

24. Kreutz R: Pharmacodynamic and pharmacokinetic basics of rivaroxaban Fundam Clin Pharmacol 2012, 26:27-32.

doi:10.1186/1423-0127-20-17

Cite this article as: Chang et al:: Rivaroxaban modulates electrical and mechanical characteristics of left atrium. Journal of Biomedical Science $201320: 17$

\section{Submit your next manuscript to BioMed Central and take full advantage of:}

- Convenient online submission

- Thorough peer review

- No space constraints or color figure charges

- Immediate publication on acceptance

- Inclusion in PubMed, CAS, Scopus and Google Scholar

- Research which is freely available for redistribution 